\title{
Residues Analysis of Organochlorine Pesticides in Fish, Sediment and Water Samples from Tekeze Dam, Tigray, Ethiopia
}

\section{Teklit GA*}

Department of Chemistry, College of Natural and Computational Science, Mekelle University, Mekelle, Ethiopia

\begin{abstract}
The study was conducted to assess the levels of organochlorine $(\mathrm{OC})$ pesticide residues in Lake TeKeze dam have been investigated using water, sediment and fish (Labeobarbusspp, Clariasgariepinus and Oreochromis niloticus) samples as a case study to find out the extent of pesticide contamination and accumulation in the lake. Six OC pesticides namely DDT, DDE, Lindane, Endosulfan, Heptachlor and Chlordane were analyzed in four sites at two seasons. Water samples were processed using a liquid-liquid extraction technique and gas chromatograph equipped with electron capture detector (GC-ECD). Soxhlet extraction was used for fish and sediment samples followed by clean up and gas chromatograph. DDE was the predominant residue in all the samples analyzed, at the mean concentrations of 0.052 $\mathrm{ppb}, 9.80 \mathrm{ppb}$ and $4.81 \mathrm{ppb}$ in water, sediment and fish samples, respectively. The lowest levels of OC pesticides were related to Heptachlor and Chlordane which none of them were found in water samples. It also indicated the extensive presence and usage of these pesticides in the study environment, which include recent use of this pesticide for agricultural purposes. Thus, the use of these pesticides to control pest by farmers within the study area with little or no knowledge must be checked through adequate control of the trade and use of pesticides and the enforcement of appropriate sanctions.
\end{abstract}

Keywords: Pesticides; Organochlorine; Pollution

\section{Introduction}

Various activities such as farming, fishing, forestry, construction, mining, urban development and land pollution occurring in or near the watershed of a reservoir could bring about water quality problems and disruption in fish [1]. Chlorinated organic pesticides are very stable in both fresh and salt water and are resistant to photo degradation [2]. They will disappear from the water with secondary mechanisms such as, absorption on sediment, biological breakdown by microflora and fauna, and absorption by fish through gills, skin and feeding. They are poorly hydrolyzed and slowly biodegrades in environment. Therefore, these compounds are persistent in food chains and are readily accumulated in animal tissues. Fish absorb these compounds directly by water or by ingesting contaminated food. In particular, Organochlorine insecticides are highly stable under different environmental conditions and persistent nature and chronic adverse effects on wildlife and humans [3].

Persistent organic pollutants (POPs) such as polychlorinated biphenyls (PCBs) or pesticides including dichlorodiphenyltrichloroethane and its metabolites (DDTs), hexachlorobenzene (HCB) or isomers of hexachlorocyclohexane (HCHs) have been known as global contaminants of the environment for decades. Pesticide is a general classification that includes insecticides, rodenticides, fungicides, herbicides and fumigants. Although pesticides may be selectively toxic to these forms of life, they may still be toxic to man if food contaminated by them is ingested. Pesticides are known to be toxic to man [4]. Some of the symptoms of pesticides poisoning include irritation, dizziness, tremor, tonic and chronic convulsion [5]. DDT in particular can block potassium influx across the membranes of nerve fibres and causes increase negative after potentials. DDT also induces the mixed function oxidize system thereby altering the metabolism of xenobiotics and steroid hormones [4]. Organochlorine pesticides are among the first set of pesticides in use and still in use in Nigeria despite their ban in developed countries due to the associated problems of indiscriminate potency and persistency. The chemical stability of these compounds, their high lipid solubility and toxicity to human and animals [6,7], has led government and researchers to be concerned with their presence in the environment. Many ignorant farmers, fishermen and some other users have abused their use for agricultural and fishing purposes. Being persistent and toxic, they pose serious environmental and health hazards, not only in the areas of applications, but up the food chain as the receiving water body contains other edible zooplanktons apart from fish that ingest these toxic chemicals which reside mostly in the fatty parts of their bodies. Consequently, bioaccumulation and biomagnifications takes place up the food chain [8].

The presence of pesticides in water (particularly organics that is aromatic chlorinated hydrocarbons) impacts objectionable and offensive taste, odours and colors to fish and aquatic plants even when they are present in low concentrations [9]. The organochlorine (OC) pesticides are among the major types of pesticides, notorious for their high toxicity, their persistence in the physical environment and their ability to enter the food chain [10]. Although the production and use of many types of OCs and organophosphorus (OPs) have been severely limited in many countries including Nigeria, they are, nevertheless, still being used unofficially in large quantities in many parts of Nigeria, and in other developing countries because of their effectiveness as pesticides and their relatively low cost [10].

Pesticide residues problems in the fish tissues are serious, as reflected by the high pesticides concentrations recorded in the water and sediments [11]. The gills are directly in contact with water. Therefore,

*Corresponding author: Teklit GA, Department of Chemistry, College of Natural and Computational Science, Mekelle University, Mekelle, Ethiopia, Tel: +251344407608; E-mail: teklitgeb@gmail.com

Received November 30, 2015; Accepted December 28, 2015; Published January 02, 2016

Citation: Teklit GA (2016) Residues Analysis of Organochlorine Pesticides in Fish Sediment and Water Samples from Tekeze Dam, Tigray, Ethiopia. J Environ Anal Toxicol 6: 342. doi:10.4172/2161-0525.1000342

Copyright: () 2016 Teklit GA. This is an open-access article distributed under the terms of the Creative Commons Attribution License, which permits unrestricted use, distribution, and reproduction in any medium, provided the original author and source are credited. 
the concentration of pesticides in gills reflects their concentration in water where the fish live, whereas the concentrations in liver represent storage of pesticides in the water [12]. Sediments are important sinks for various pollutants like pesticides and also play a significant role in the remobilization of contaminants in aquatic systems under favorable conditions and in interactions between water and sediment. Fish samples can be considered as one of the most significant indicators in fresh water systems for the estimation of pesticides pollution level [10]. The region of accumulation of pesticides within fish varies with the route of uptake. Their potential use as bio monitors is therefore significant in the assessment of bioaccumulation and bio magnifications of contaminants within the ecosystem [12]. Many dangerous chemical elements, if released into the environment, accumulate in the soil and sediments of water bodies. The lower aquatic organisms absorb and transfer them through the food chain to higher trophic levels, including fish. Under acidic conditions, the free divalent ions of many metals may be absorbed by fish gills directly from the water [12]. Hence, concentrations of pesticides in the organs of fish are determined primarily by the level of pollution of the water and food under certain conditions, chemical elements accumulated in the silt and bottom sediments of water bodies can migrate back into the water.

TeKeze Dam is found at a co-ordinates $13^{\circ} 21^{\prime}$ North and $38^{\circ} 45^{\prime}$ East, at an altitude of $970 \mathrm{~m}$ above mean sea level, whereas the crest of the dam is $1145 \mathrm{~m}$ above sea level and the substation on the right bank plateau is at approximately 1300 masl and approximately $80 \mathrm{~km}$ west of the town of Mekelle. The dam is located in a steep, narrow gorge, which the river has carved through the surrounding plateau during the course of many millions of years [13-15].

The TeKeze River, which forms the boundary between the Regions of Tigray and Amhara, flows northwards and is a major tributary of the Atbara River, which is itself a tributary of the Nile. Previously undeveloped, the TeKeze is now generating hydroelectric power and makes a significant contribution Ethiopia's economy. In addition, the reservoir that has been formed upstream of the dam has potential for the development of commercial fisheries and tourism, while, downstream, regulation of the river has potential benefits for the development of irrigation schemes.

Lack of knowledge of the use and the effects of these pesticides among small and large scale farmers has resulted in their misuse and consequently the waste generated flows into TeKeze Dam and may contaminates the Dam with a variety of pesticides acting as point sources. Such contaminations might accumulation in the various organs of fishes; such accumulation may affect humans and other species that depend on such fish as food.

This work, therefore, seeks to provide base line information on levels of pesticide residues including DDT, DDE, Lindane, Endosulfan, Heptachlor and Chlordane in fish (Labeobarbusspp, Clariasgariepinus and Oreochromis niloticus), sediments and surface waters of the TeKeze dam through two seasons that will assist in a scientific assessment of the impact of pesticides on public health, agriculture and the environment in the surrounding region especially in Tigray, Ethiopia.

\section{Materials and Methods}

Fish, sediment and water samples were obtained from four various sites of the Dam (Figure 1). Samples were collected from surface parts of the water and sediment. Also, each sampling was carried out in three replicates. A total of 24 samples each of sediments and water were collected randomly. However, fish samples were 7 because of little rainfall in recent years which has caused a decrease in water depth leading to limited dispersal of fish species. All samples collected (water, sediments and fish) were immediately stored in an ice-chest at $4^{\circ} \mathrm{C}$ and transported to the laboratory for analysis.

\section{Extraction of OC pesticides in water samples}

In the laboratory, using liquid-liquid extraction (LLE) as described in APHA [16], the total amount of each surface water sample $(800 \mathrm{ml})$ was filtered with Whatman filter paper (i.d. $70 \mathrm{~mm}$ ) to remove debris and suspended materials and then poured into a 2 liter separatory funnel. For the first LLE, the mixture of $100 \mathrm{ml}$-hexane and dichloromethane $(1: 1 \mathrm{v} / \mathrm{v})$ was added and shaken vigorously for $2 \mathrm{~min}$ before two phase separation. The water-phase was drained from the separatory funnel into a $1000 \mathrm{ml}$ beaker. The organic-phase was carefully poured into a glass funnel containing $20 \mathrm{~g}$ of anhydrous sodium sulfate through a $200 \mathrm{ml}$ concentrator tube. Following the second and third LLE, the water-phase was poured back into the separatory funnel to re-extract with $50 \mathrm{ml}$ of the same solvent mixture. The extract was concentrated to the volume of $2 \mathrm{ml}$ under a gentle stream of nitrogen using rotary evaporator and then analyzed with Gas Chromatography with micro Electron Capture Detector (GC-iECD) [17].

\section{Extraction of OC pesticides in fish and sediment samples}

The muscle tissues of the fish samples were ground in a blender to obtain a homogenous composite, while the sediments were air-dried. OC residues in sediments and fish samples were extracted using Soxhlet Extraction [18]. A $10 \mathrm{~g}$ sample was placed into a beaker containing $50 \mathrm{~g}$ anhydrous sodium sulfate and mixed thoroughly. The sample mixture was transferred to an extraction thimble and placed in a Soxhlet extractor. The mixture was extracted with $150 \mathrm{ml}$ of acetone: $\mathrm{n}$-hexane $(20: 80 \mathrm{v} / \mathrm{v})$ at $50^{\circ} \mathrm{C}$ for $4 \mathrm{~h}$. The extracts were filtered, concentrated to $1 \mathrm{ml}$ using vacuum rotary evaporator. Each of the raw extracts was then dissolved in $10 \mathrm{ml}$ hexane and passed through pre-conditioned octadecyl C- 18 columns at a rate of $2 \mathrm{ml} \mathrm{min} \mathrm{G} \mathrm{to} \mathrm{clean} \mathrm{up.} \mathrm{The} \mathrm{column}$ was washed with $1 \mathrm{ml}, 30 \%$ methanol followed by $1 \mathrm{ml}$ ultrapure water and was allowed to dry. The sample (analyte) which was trapped in the column was eluted 5 times with $0.5 \mathrm{ml}$ aliquots of hexane to recover the pesticide residues. Hexane in the sample was then allowed to evaporate off leaving the residue alone in the vial. Dried sample was dissolved in $1 \mathrm{ml}$ portion of hexane, mixed thoroughly with a whirl mixer and then transferred to auto sampler vials ready for gas chromatography [5].

Statistical analyses were carried out by analysis of variance (ANOVA) using SPSS 15 software. Mean values were analyzed by the Duncan's test.

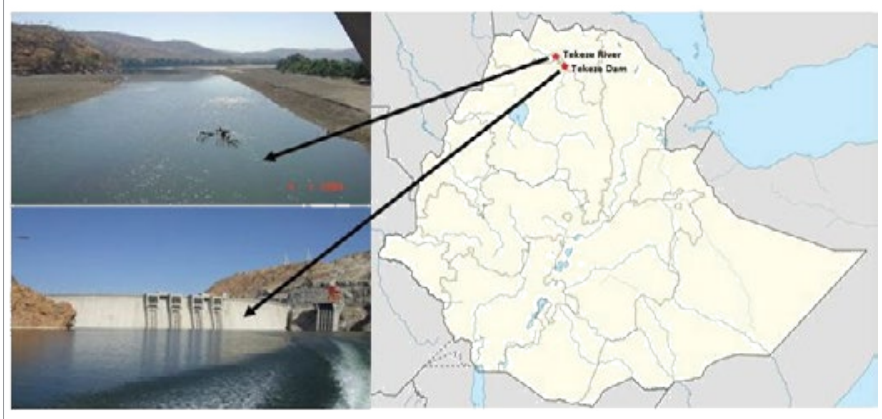

Figure 1: TeKeze River Dam 


\section{Results and Discussion}

TeKeze Dam is surrounded by farm lands. A large amount of chemicals (fertilizers and pesticides) are used there by farmers which can enter the wetland through running waters and subterranean canals. Also, garbage and wastewaters are poured in the wetland by inhabitants. All of these factors may lead to the contamination of TeKeze dam.

Results from the study have been shown in Tables 1, 2 and 3 which are related to the concentration of OC residues in water, sediment and fish samples, respectively. DDT was detected in $54 \%$ of water samples, $75 \%$ of sediments and $84 \%$ of fish samples. The associated figures for mean concentrations were $0.016 \mathrm{ppb}, 4.980 \mathrm{ppb}$ and 4.112 $\mathrm{ppb}$. The ratios of incidence as well as the concentrations of DDE, a metabolite of DDT, in all the three sample types were higher than those recorded for DDT which was $84 \%, 96 \%, 94 \%$ in water, sediment and fish samples, respectively. This observed trend could be attributed to the decomposition and bioaccumulation of the DDT used in the past. DDE is more stable than DDT and decomposes more slowly by micro-organisms, heat and ultraviolet rays [4]. Neither chlordane nor heptachlor was detected in the water samples showing that the farmers around the lake do not use them in their farming activities. However, these organochlorine pesticides were measured in fish and sediment samples, which is because they are less soluble in water. They, therefore, accumulate in fishes and sediments when they are discharged into water bodies. Frequency of detection (incidence) and concentration of chlordane and heptachlor measured in sediments were higher than those recorded for fish samples. Chlordane was detected in $24 \%$ of sediment samples at concentrations ranging from 0.28 to $0.42 \mathrm{ppb}$, while it was detected in $12 \%$ of the fish sample and their concentrations ranged between 0.35 and $0.56 \mathrm{ppb}$. Heptachlor was detected at an average concentration of $0.081 \mathrm{ppb}$ and $0.041 \mathrm{ppb}$ in sediments and fish, respectively.

Lindane was detected in $68 \%$ of water samples, $72 \%$ of sediment samples and $39 \%$ of fish samples analyzed with the highest concentration of $14.21 \mathrm{ppb}$ occurring in sediments. This result suggests lindane is more prevalent and persistent in the sediments than in water and then in fish. The average concentration of lindane in sediments was about 50 -folds the average concentration in fish and 120-folds the average concentration in water. It is therefore expected that lindane levels in fish will rise with time as they utilize the water and the sediments in the Dam.

Endosulfan, a broad spectrum contact insecticide and acaricide, is another pesticide used by many farmers. The highest concentration of Endosulfan (15.22 ppb) was detected in the sediment samples, however, the highest occurrence of detectable concentrations was found in water (60\%). Endosulfan level in fish, on the average, is 16 times that found in water samples. This suggests that the residues in the water are accumulated and concentrated in the fish. Mean level of Endosulfan in the sediments is about 13 times the levels measured in fish. Bio concentration of Endosulfan in fish could therefore arise.

In general, the concentration of OC pesticides in water was lower than sediments and fishes which was highly significant (P-0.05), because these pesticides are lipophilic and are not soluble in water. This fact can ease the accumulation of OC pesticides in micro-organism tissues.

The mean total concentration of organochlorine residues in water samples of the dam was $0.023 \mathrm{ppb}, 0.030 \mathrm{ppb}, 0.054 \mathrm{ppb}$ and $0.010 \mathrm{ppb}$, respectively generally, the highest concentration of OC pesticides was seen in nearest to the farm land. It may be due to the abundance of farm lands around this site which have sharp slopes toward this part of the lake, so pesticides and other chemical materials can enter there more easily. However, the lowest concentration of organochlorine residues was related to center part of the dam. Because there is a slow current toward this part and the contaminants cannot accumulate there.

Kairu et al. [19] reported the rate of chlorine pesticides in muscle tissue of fishes and DDE was the predominant target compound. The results obtained in this study generally agree with their findings.

The levels of most of the residues in fish were higher than those found in water. Organochlorine pesticide residues in the lake are likely to originate from nonpoint sources via runoff, atmospheric deposition and leaching due to agricultural applications and vector control practices [20-27]. The lake sediments act as a sink for the persistent contaminants, whose resuspension during the lake's mixing may increase pesticide bioavailability and accumulation in the fish. Pesticide pollution to the lake is therefore, likely to pose a danger to both aquatic organisms and humans.

\section{Conclusion}

This research the first in the dam. The mean values and ranges of residues found in fish were significantly below the FAO/WHO maximum acceptable limits in fish and sea food however increased monitoring is recommended.

\section{Acknowledgements}

The authors would like to thank the Ethiopian Agricultural instate for doing GC and Aquatic ecology lab of Mekelle University for collaboration in some parts of this study.

\begin{tabular}{|l|l|l|l|l|}
\hline Pesticide & Mean (ppb) & Standard Deviation (SD) & Range (ppb) & Percentage \\
\hline DDT & 0.016 & 0.003 & $0.12-0.24$ & 54 \\
\hline DDE & 0.055 & 0.008 & $0.05-0.14$ & 84 \\
\hline Chlordane & - & - & - & - \\
\hline Heptachlor & - & - & - & - \\
\hline Lindane & 0.058 & 0.012 & $0.45-1.50$ & 68 \\
\hline Endosulfan & 0.046 & 0.009 & $0.30-0.46$ & 60 \\
\hline
\end{tabular}

Table 1: Levels of organochlorine pesticide residues in water samples of TeKeze dam.

\begin{tabular}{|l|l|l|l|l|}
\hline Pesticide & Mean (ppb) & Standard Deviation (SD) & Range (ppb) & Percentage \\
\hline DDT & 4.980 & 1.66 & $4.21-6.18$ & 75 \\
\hline DDE & 9.840 & 2.85 & $12.27-30.43$ & 96 \\
\hline Chlordane & 0.074 & 0.03 & $0.28-0.42$ & 24 \\
\hline Heptachlor & 0.081 & 0.04 & $0.24-0.44$ & 36 \\
\hline Lindane & 6.920 & 1.18 & $3.06-14.21$ & 72 \\
\hline Endosulfan & 10.622 & 1.72 & $4.12-15.22$ & 46 \\
\hline
\end{tabular}

Table 2: Levels of organochlorine pesticide residues in sediment samples of TeKeze dam

\begin{tabular}{|l|l|l|l|l|}
\hline Pesticide & Mean (ppb) & Standard Deviation (SD) & Range (ppb) & Percentage \\
\hline DDT & 4.112 & 1.12 & $3.50-5.56$ & 84 \\
\hline DDE & 4.864 & 1.42 & $4.18-8.26$ & 94 \\
\hline Chlordane & 0.024 & 0.008 & $0.35-0.56$ & 12 \\
\hline Heptachlor & 0.041 & 0.01 & $0.28-0.58$ & 34 \\
\hline Lindane & 0.138 & 0.06 & $0.65-1.47$ & 39 \\
\hline Endosulfan & 0.816 & 0.12 & $0.94-2.14$ & 33 \\
\hline
\end{tabular}

Table 3: Levels of organochlorine pesticide residues in fish muscle tissue samples of TeKeze dam. 
Citation: Teklit GA (2016) Residues Analysis of Organochlorine Pesticides in Fish, Sediment and Water Samples from Tekeze Dam, Tigray, Ethiopia. J Environ Anal Toxicol 6: 342. doi:10.4172/2161-0525.1000342

\section{References}

1. Abu-Hilal $\mathrm{AH}$ (1993) Observations on heavy metal geochemical association in marine sediments of the Jordan Gulf of Aqaba. Mar Pollut Bull 26: 85-90.

2. Abu-Hilal AH, Badran MI (1990) Effect of pollution sources on metal concentration in sediment cores from the Gulf of Aqaba (Red Sea). Mar Pollut Bull 21: 190-197

3. Abu-Hilal AH (1987) Distribution of trace elements in nearshore surface sediments from the Jordan Gulf of Aqaba (Red Sea). Mar Pollut Bull 18: 190193.

4. Abu-Hilal AH, Badran M, Vatigelas J (1988) Redistribution of trace elements in Callichirus laurae burrows (Crustacea, Thalassinidea), Jordan Gulf of Aqaba (Red Sea). Mar Environ Res 25: 233-248.

5. Akiwumi FA, Butler DR (2008) Mining and environmental change in Sierra Leone, West Africa: a remote sensing and hydrogeomorphological study. Environ Monit Assess 142: 309-318.

6. Barlas NA (1999) Study of heavy metal concentrations in varoius environments and fishes in the Upper Sakaryia River Basin, Turkey. Environ Toxicol 14: 367 373.

7. Begüm A, Amin M, Kaneco S, Ohta K (2005) Selected elemental composition of the muscle tissue of three species of fish, Tilapia nilotica, Cirrhina mrigala and Clarius batrachus, from the fresh water Dhanmondi Lake in Bangladesh. Food Chemistry 93: 439-443.

8. Canli M, Atli G (2003) The relationships between heavy metal (Cd, Cr, Cu, Fe $\mathrm{Pb}, \mathrm{Zn}$ ) levels and the size of six Mediterranean fish species. Environ Pollut 121: 129-136.

9. Chen CY, Folt CL (2000) Bioaccumulation of arsenic and lead in a freshwater food web. Environ Sci Technol 34: 3878-3884.

10. Chiou CT (2002) Bioconcentration of organic contaminants, in Partition and Adsorption of Organic Contaminants in Environmental Systems: Hoboken, NJ. John Wiley \& Sons, Inc. p: 257.

11. CIFA (1994) Review of Pollution in the African aquatic environment. FAO Tech Paper 25: 118

12. Deb SC, Fukushima T (1999) Metals in aquatic ecosystems. Mechanisms for uptake, accumulation and release. Int Environ Stud 56: 385-393.

13. Farkas A, Salanki J, Varanka I (2000) Heavy metal concentrations in fish of Lake Balaton. Lakes and Reservoirs, Research and Management 5: 271-279.

14. Federal Environmental Protection Agency (FEPA) (2003) Guidelines and Standards for Environmental Pollution Control in Nigeria. p: 238
15. Fernandes C, Fontaínhas-Fernandes A, Cabral D, Salgado MA (2008) Heavy metals in water, sediment and tissues of Liza saliens from Esmoriz-Paramos lagoon, Portugal. Environ Monit Assess 136: 267-275.

16. Giesy JP, Weiner JG (1977) Frequency distribution of trace metal concentrations in five freshwater fishes. Trans Am Fish Soc 106: 393-403.

17. Mwevura H, Othman C, Mhehe L (2002) Organochlorine Pesticide Residues in Edible Biota from the Coastal Area of Dar es Salaam City. Western Indian Ocean J Mar Sci 1: 91-96.

18. Mugachia JC, Kanja L, Gitau F (1992) Organochlorine pesticide residues in fish from Lake Naivasha and Tana River, Kenya. Bull Environ Contam Toxicol 49: 207-210.

19. Kairu JK (1994) Pesticide residues in birds at Lake Nakuru, Kenya. International Journal of Salt Lake Research 3: 31-48.

20. Wasswa J, Kiremire BT (2004) Pesticide residue distribution in sediment and fish Samples from the ugandan side of lake Victoria. The african network for chemical analysis of pesticides Arusha International Conference Centre, $8^{\text {th }}$. $11^{\text {th }}$ August.

21. PCPB Banned products (2009) Kenya pest control products board.

22. Jalili SH, Ilkhanipour M, Heydari R, Farshid AA, Salehi S (2007) The Effects of Vitamin $E$ on Endosulfan - Induced Oxidative Stress in Rat Heart. Pakistan Journal of Nutrition 6: 375-380.

23. Wandiga SO, Yugi MW, Barasa MW, Jumba IO, Lalah JO (2002) The distribution of organochlorine pesticides in marine samples along the Indian Ocean Coast of Kenya. Environ Technol 23: 1235-1246.

24. Wandiga SO (2001) Use and distribution of Organochlorine pesticides, The future in Africa. Pure Appl Chem 73: 1147-1155.

25. Deichmann WB (1981) Halogenated cyclic hydrocarbons, In: Patty's Industria Hygiene and Toxicology, 3rd rev (edn.) Clayton GD, Clayton FE (Eds). John Wiley and Sons, Inc. NY 2B. pp: 3603-3769.

26. Mavura WJ, Wangila PT (2014) Distribution of Pesticide Residues in Various Lake Matrices: Water, Sediment, FishAnd Algae, The Case Of Lake Nakuru, Kenya. The african network for chemical analysis of pesticides, Arusha.

27. Getenga ZM, Kengara FO, Wandiga SO (2004) Determination of organochlorine pesticides in soil and water from river Nyando drainage system within Lake Victoria Basin, Kenya. Bull Environ Contam Toxicol 72: 335-343. 